\title{
The management of participatory cultural initiatives: learning from the discourse on intellectual capital
}

\author{
Martin Piber $^{1} \cdot$ Paola Demartini $^{1,2} \cdot$ Lucia Biondi $^{1,2}$
}

Published online: 3 September 2018

(C) The Author(s) 2018

\begin{abstract}
Based on previous research that highlights some gaps in the study of the new phenomena of Participatory Cultural Initiatives (PCIs), this paper addresses the need to understand how the relevance of those initiatives is perceived, tentatively measured and communicated to strategic stakeholders. With this, we want to investigate a possible contribution of the discourse on Intellectual Capital (IC) and Intangible Assets for the cultural sector in general and PCIs in detail. The IC perspective is adopted as a boundary object to analyse the key actors' behaviours concerning PCIs, following a performative approach. In doing so, this field research applies a case study method of analysis by investigating two PCIs in Italy: Big City Life, a street art district in Tor Marancia (Rome) and the project of Matera as European Capital of Culture 2019. Data have been gathered through both primary (interviews) and secondary (official documents, social media, websites and press releases) sources of evidence. The analysis is mainly developed at a micro (single organisation) and meso (district/ city) level. Given the originality of the topic whose research is still at an infancy stage and without a well-grounded theory, we seek to gain significant insights into this new issue by applying an exploratory approach. Through the IC lens, it is possible to gain a better understanding of how the PCIs' impact is assessed and communicated to its stakeholders. Evidence shows that narratives and visualisations play a crucial role by supporting comprehension of the PCIs' key aspects and their interwoven relations. A condition for narratives and visualisations to be accepted as legitimation tools is the development of a trust relationship among stakeholders. As a result, the impact of PCIs has dimensions and interwoven aspects which are not amenable for traditional performance measures. In summary, it is possible to state that PCIs trigger a focus on talking and showing to understand, instead of a focus on measuring to understand. The paper discusses how the understanding and management of PCIs can improve with lessons learnt from the discourse on IC and with reference to Habermas' theory of communicative action. Primarily, we focus on the use of narrative and visual representations by key actors to communicate with strategic stakeholders to gain trust and legitimation.
\end{abstract}

Extended author information available on the last page of the article 
Keywords Participatory cultural initiatives · Impact, performance measurement · Intellectual capital

\section{Introduction}

A participatory approach in culture highlights not only the relevance of cultural initiatives for society and social entities as a whole but also introduces a rather subjective dimension of impact on individuals like personal reflections. Thus, a Participatory Cultural Initiative (PCI) "[...] highlights the subjective relevance of individual contributions and strengthens the feeling of being socially connected among each other" (Piber et al. 2017).

Public and private actors-ranging from supranational institutions (i.e., UNE$\mathrm{SCO}, \mathrm{EU})$ to single individuals - are interested in such initiatives that contribute to the quality of life (e.g., Comunian 2010). The expected benefits and the value of culture for the society and the economy gain attention at a continually increasing rate (Belfiore 2015). Notwithstanding a prolific body of knowledge on cultural initiatives, we need more insights on how they can contribute to creating value for the society, what impact we can expect and how we can account for the results.

This research highlights the experience of two cases to understand the contribution of different PCIs for different stakeholders better. A particular focus lies in different strategies to make impact visible to others. Literature in the field of art and culture policy-making defines impact as a demonstrable contribution to society and the economy and considers it as a proxy for public value (Belfiore 2002, 2013, 2015; Belfiore and Bennett 2008; O'Brien 2010; Oancea 2013). In this stream of research, the primary focus of the research asks "how to engineer and then measure convincingly the impact that is being claimed, promised or expected?" (Belfiore 2013). Whereas in our research we follow a performative approach (Denzin 2001), and we want to understand how main actors understand, assess and communicate the impact of PCIs to engage stakeholders and gain legitimacy. Therefore, we will analyse how the main actors communicate and account for PCIs.

Grounded on the fact that cultural organisations operate in an environment mainly based on intangible assets, both on the side of production and the side of outcomes (Chong 2009), we want to understand the possible contribution of the discourse on Intellectual Capital (IC) and Intangible Assets to the cultural sector in general and to PCIs in detail. At the present state, the debate on Intellectual Capital Accounting Research (ICAR) (Guthrie et al. 2012) has paid very little attention to the cultural sector (for few exceptions, e.g., Donato 2008; Sundström 2011; Dumay 2014). On the other hand, art management scholars have paid little attention to the IC discourse (Chiaravalloti and Piber 2011). A special focus of the IC literature research was dedicated to a Habermasian approach concerning his theory on communicative action. As it elaborates on the relation between different actors, it supports a deeper understanding of PCIs and their communication to stakeholders.

Consequently, this paper addresses the following research question: how can an IC lens help us to understand, assess and communicate the multidimensional impact of PCIs to stakeholders? 
The paper discusses how the application of different paradigms to understand impact can be improved with insights from the discourse on IC in action (Giuliani and Marasca 2011; Chiucchi 2013; Dumay and Garanina 2013; Zambon 2016). We use as well the literature in the area of evaluation and impact to better understand the performance and relevance of PCIs. In particular, we will examine to what extent measures and narrative representations contribute to gaining trust and legitimation in PCIs. In doing so, we view this paper as a basis for further research, not only in the cultural sector but also in many other contexts where co-creation and co-participation processes boosted by new technologies claim new ways to frame organisational environments.

The paper is structured as follows. In Sect. 2, the multidimensional impact of PCIs is analysed under different perspectives. In Sect. 3 a review of the relevant literature on the IC discourse in arts and cultural initiatives is presented. In this regard, the paper draws on different streams of research, namely: (i) performance measurement in the cultural sector (ii) Intellectual Capital Accounting Research and (iii) IC communication under a Habermasian perspective. Section 4 details the methodology, focusing on the selection of the case studies and the research protocol followed. Sections 5 and 6 describe, respectively, the cases and their performance management practices, summarising the findings of the field research. Then, Sects. 7 provides a discussion of evidence, based on a critical and performative analysis of IC practices in action. Finally, Sect. 8 draws some overall conclusions.

\section{The multidimensional impact of PCls}

PCIs are cultural events highlighting the participation of different people. In general, they represent a special kind of cultural projects where the audience, or part of it, is not only the "user" but also the "actor" of the initiative, being involved in its co-creation in various ways (e.g., see Kelly 2014 on the notion of participatory art). Examples are singular performances with the engagement of visitors/spectators, as well as more extensive projects like the participation of a city in the European Capitals of Culture programs.

This paper contributes to the management of such initiatives by questioning the impact of PCIs. Impact entails the generation of "lasting changes in the lives of people and their societies. [We have to ask:] Are the activities and outputs leading to sustained improvements in the lives of affected people?" (Ebrahim and Kasturi Rangan 2014: 118, 123).

Profit organisations have mainly a one-dimensional target, i.e., earnings, whereas cultural organisations and PCIs have a rather complex structure of targets and focus more on intangible results. The difference and the change triggered are multi-dimensional, and the value generation targets a wide range of stakeholders, including users/recipients of a specific cultural initiative, funders, organisers/project curators, communities, and citizens. Cultural outcomes are mostly assessed by concepts such as the quality of the artistic performance, the subjective impact on individuals feelings and thoughts, the social impact on local stakeholders and communities and the power of social disruption. Hence, there are good reasons to 
consider, demonstrate and communicate the impact of PCIs: firstly, to legitimise public spending; secondly, to fulfil the accountability requirements of key stakeholders (especially funders); thirdly, to improve their quality in various dimensions; and fourthly, to better understand and learn about the consequences.

Interestingly enough, there is quite a considerable gap in the literature in terms of studies on impact for the whole not-for-profit sector in general (e.g., Ebrahim and Kasturi Rangan 2014: 119), and for PCIs in particular. Notably, the impact of PCIs is not extensively examined.

Managerial tasks in the cultural sector are described by Kushner and Poole (1996) and focus on satisfying audiences, donors and volunteers, identifying and obtaining financial and human resources, efficiently organising resources into technologies to present arts performances and achieving performing arts program objectives. Hence, performance measurement technically looks at the achievement of the goals set in these areas.

At the moment, an increased need to account for impact in the area of arts and culture has emerged. That means that more and more stakeholders are interested in impact studies, in order to understand the final results of initiatives. However, on closer examination, any construct of impact is more than just the additive connection of different contributors to the performance. It can be better explained as the evaluation of connected social processes.

Nevertheless, many approaches implicitly accept the supremacy of the economic paradigm (e.g., Belfiore 2015). Recently, social cohesion and societal well-being complement economic effects. Somehow culture and the arts are means to reach economic targets (Belfiore and Bennett 2010; Holden 2006). In a similar vein, Gilhespy (2001) focuses on an indicator system which should be customised to the organisation. Krug and Weinberg (2004) propose a system that evaluates the organisation's contribution to mission, money, and merit. The mission addresses whether the performance meets the goals of the mission. The dimension of money asks whether the financial performance is adequate, and the dimension of merit covers whether things are done right in terms of quality. More broadly, Gstraunthaler and Piber (2012: 35) question whether the multifaceted dimensions of culture and the arts can be captured with performance indicators. For the area of culture, they state that "[...] the internal performance measurement and evaluation [...] relies largely on peers giving judgements based on their experience and expertise." This exemplifies the need for research to understand and assess cultural initiatives beyond quantitative measures.

The New Public Management (NPM) logic starts with inputs and approaches via activities, outputs and outcomes reflecting the long-term societal impact (e.g. Ebrahim and Kasturi Rangan 2014: 121). However, PCIs also make a difference beyond clearly observable outputs and outcomes: the predominantly subjective effect on each participating individual. In this context, Holden proposes three categories of cultural value: instrumental, institutional and intrinsic value. "Intrinsic values are the set of values that relate to the subjective experience of culture intellectually, emotionally and spiritually" (Holden 2006: 14). Culture is merely relevant for what it is for itself. The instrumental value focuses on the economic and social purpose of cultural activities, and, finally, the institutional 
value represents the service of a cultural organisation for the public. PCIs are very good examples that can demonstrate all three categories.

Recapitalising the literature, we can find the following dimensions of impact: the touristic/economic dimension, the value for urban and regional communities and development, the contribution to identity building processes of cities and regions, the social inclusion/social cohesion, the learning and education dimension and the individual and emotional dimension beyond the aforementioned issues.

On this basis, we understand impact not only as a phenomenon addressing organisations, institutions and public entities like cities or regions but also as a considerable change in the thoughts, ideas, and lives of people. Moreover, different time spans of impact can be considered; we can focus on the immediate result of an initiative as well as on the long-lasting effect on a city or community. Both are relevant for the assessment of PCIs.

Ultimately, talking about impact means dealing with the complexity of interwoven processes and targets, in which it is challenging to disentangle univocal and general cause-effect relationships. Overall, the impact of PCIs is subjective and not easy to define. Therefore, respective evaluative practices also have to deal with ambiguity.

For the cultural sector, in general, and for PCIs, in detail, both facts, as a result, lead us to deal mostly with intangible phenomena, which, therefore, will be analysed against the background of the discourse of IC and intangible assets.

\section{An IC perspective for cultural organisations}

In the knowledge economy, intangible assets are fundamental economic factors that produce wealth (Haskel and Westlake 2017). Hence, in the last twenty years, the discourse of IC has become a lens, for researchers, to analyse value creation not only at a micro-level, such as in private organisations (e.g., Edvinsson 2013 for a detailed literature review), public sector (Fletcher et al. 2003; Guthrie and Dumay 2015) and non-profit entities (Kong 2010) but also at a meso-level, concerning local communities (Bounfour and Edvinsson 2012; Schiuma et al. 2008) and eco-systems (Guthrie et al. 2017), and, finally, at a national level (Lin and Edvinsson 2010).

Even though cultural organisations operate in an environment mainly based on intellectual and intangible resources, both on the side of production and the side of outcomes (Chong 2009), within the discourse of IC, little attention has been devoted to the cultural sector (with only some exceptions, e.g., Donato 2008; Sundström 2011; Dumay 2014). Insofar, this paper opens up a generic space for a contribution of the IC perspective to conceptualise and understand the multidimensional impact of cultural initiatives better, as well as to support the sense-making process for key stakeholders. Subsequently, to cross-fertilise the IC discourse with the challenges of the cultural sector and vice versa, we will draw on the parallel debates in these two streams of research, namely arts management research and ICAR. 


\subsection{The debate on performance evaluation in arts management research}

Scholars in the field of arts and cultural organisations management have paid little attention to the IC discourse. In particular, the research on performance evaluation in the cultural sector complements the IC perspective and offers a solid basis to understand PCIs better. In their research, Chiaravalloti and Piber (2011) analyse the ethical implications of methodological settings in arts management as far as performance evaluation is concerned. They inquire "to what extent current research approaches are able to serve the needs of arts organisations and their communities" (p. 240). Some authors, like Gilhespy (2001) and Weinstein and Bukovinsky (2009) suggest a list of measurable indicators, financial and non-financial, aimed to give an accurate representation of the management performance, in line with a positivist research tradition. In particular, Weinstein and Bukonvinsky suggest a Balanced Scorecard (BSC) - for arts and cultural organisations without any major adaptation from the model that Kaplan and Norton (1992) proposed for the profit sector. The underpinning assumption is that art and cultural organisations behave in the light of a rational decision-making process. Nevertheless, in concluding his article Gilhespy (2001) notices that not every organisation in his study behaved according to a rational model, and he concludes that not all indicators were useful for catching the intangible values represented and created by cultural organisations. Other authors, like Soren (2000) and Radbourne et al. (2009, 2010) are more interested in assessing the impact that art and cultural organisations have on their visitors and their audiences' experiences. "With respect to their view of reality, the authors [Radbourne et al. 2009, 2010] embrace the idea of making instead of finding reality [...] since they are interested in how artistic quality is constructed through the experience of individuals" (Chiaravalloti and Piber 2011: 256). This refers to the understanding of impact as making a difference in terms of new thoughts and ideas of individual participants of a PCI.

Finally, the artistic evaluation for many researchers in arts management is the core element of a performance management system and is "the result of personal and collective sense-making based on unwritten rules and on intuitive forms of evaluation" (id.: 258). In order to integrate it in the general evaluation practices at an organisational level, Chiaravalloti and Piber (2011) suggest that the expertise of the artists is required "since their world will hardly be fully accessible to external observers" (ibidem).

To this end, it is worthwhile noting a shift from a rational definition of performance measurement to a more interpretive and intimate approach involving artists and culture consumers that co-participate in the culture creation process. In doing so, the experience and other intangible impacts are the focus of attention-representing turbulent soil-even for art management research, as it is not easy to determine, standardise and communicate.

Being aware of the contextual complexity of understanding and evaluating arts and culture "arts organisations adopt a variety of methods to suit their unique environments" (Chiaravalloti and Piber 2011: 260). This consideration is the key to a better understanding of PCIs as well. 


\subsection{The debate on arts organisations management in the IC research}

Before analysing the few contributions on the subject of arts and cultural organisations in the IC literature, it is useful to depict some main concepts that will then be applied in that specific context and which also constitute the reference framework of our survey.

Following a performative research approach, as suggested by Mouritsen (2006), we are interested in measuring and communicating IC because it can facilitate intervention, either from the perspective of internal readers or external ones. "If intervention and measurement are coupled, then measurement is an input rather than an output, and then measurement is not to be evaluated on its reflection of reality but rather on its ability to help actors transform their reality" (Mouritsen 2004: 257).

Mouritsen (2006) defines an IC statement as an "inscription", which assumes performativity or the ability to make a difference. "The inscription is a device that organises the world and makes it accessible. [...] IC elements develop a construction of the world. This is neither true nor false; at its highest it can be interesting, engaging, surprising, entertaining and educational and thus persuade other actors to follow the route it has prepared; or other actors can abandon it or change it. IC elements are here part of the constitution of what the knowledge-based economy can become rather than only about what it is". (id.: 826). As Callon and Latour (1981: 286) explain, an inscription "makes changes in the set of elements and concepts habitually used to describe the social and the natural worlds".

From this perspective, information is input rather than output, and the researcher's concern is to study how IC information and communication play a role through a sensemaking process. From an accounting perspective "sensemaking relates to how the members of an organisation actively give meaning to the communicated accounts" (Catasus et al. 2009).

Another researcher's concern is about the ways and means to represent IC (i.e., by numbers, narrative, sketches) in order to trigger learning, legitimation, achievement or change (Catasús and Gröjer 2006). Relationships between numbers and action are complex. As Giddens (in Beck et al., 1994) says, numbers have to be explained through a narrative, storytelling to mobilise actors towards IC achievements ("there is no number without a narrative"). Catasús et al. (2007) added that measuring is not a means to activate the organisation per se. Rather, measurements support issues that are already important to the organisation ("what gets talked about gets done, especially if there are numbers", id: 505). The use of narrative and storytelling for explaining strategy, managing transformation and engaging employees and other stakeholders is a powerful instrument for managing and sensemaking in contemporary businesses (e.g., Brown et al. 2005). Also, Weick and Browning argue for the use of narratives, metaphors, and storytelling, which can also make ambiguities and complexities understandable: "Narration, much like metaphor, has power precisely because it captures complex experiences that combine sense, reason, emotion and imagination. Narration stirs all those elements together and preserves their interactions in a compact summary that can be reconstructed starting from any one of its parts" (Weick and Browning 1986: 250). 
Beyond performance measures and narratives, visualisations have gained momentum in IC communication. Mouritsen et al. (2001) argue that sketches and visualisation approaches make the context understandable and even more relevant. Cunegan and Dumay (2009) have explained this in terms of both its effects on the communication, processing, and absorption of information (Hoffjan and Schmitting 2003), as well as the adoption of new and advanced visualisation technologies. Finally, visualisations can have a higher emotional impact supporting the sense-making process and managerial interventions.

Habersam and Piber (2003) call for a comprehensive representation of IC to better discern different IC dimensions in interactions. They elaborate four groups of IC: metric, literal, intuitive and black box capital. Only metric capital can be represented in plain-spoken performance measurement systems. Literal capital is amenable by narratives. Intuitive capital can only be experienced in an interactive way and cannot be mediated. Black box capital refers to complex experiences and remains hidden. Unconscious interpretations, in fact, are the most intangible segment of IC (e.g., Polanyi 1966). Similarly, O'Donnell et al. (2000) take a critical stance towards the measurement of IC: "[...] there is much that cannot be accurately measured or indeed precisely managed. If we adhere strictly to the illusory mantra that we must measure that which we wish to manage, then we are likely to miss out on, and perhaps remain ignorant of, or go into psychological denial with respect to, crucial aspects of this 'elusive intangible'." (ibidem: 190).

From the empirical analysis carried out by Donato (2008), we have learnt that even cultural organisations recognise the importance of IC. Nevertheless, a large majority of these organisations does not explicitly measure it. What they do is more subtle; some elements of IC are addressed via personal relationships, weekly internal meetings, public debates and internal and external "signals", in others word, IC is measured through "antennae" (Donato 2008: 390). Cultural managers are well aware of various important factors for the sustainable success of their organisations. However, they affirm that most of these factors are intangible and that there is no adequate medium for a formalised way to measure and communicate them. This paradox is undoubtedly one of the most interesting aspects we are going to investigate in our study.

One emerging factor to be addressed is the need to engage the different stakeholders involved in the process of creation, delivery, and enjoyment of cultural goods through day-by-day direct communication. Periodic and formalised communication seems to be losing a reason to be, whereas it arises the need for managers to seize timely weak signals to manage consensus.

While Donato (2008) examined measurement for managerial purposes, Sundström (2011) also adds emphasis on measurement for external reporting purposes, studying the case of a Swedish theatre. Consistent with Donato, he found that managers' decisions were based more on their "own feelings" and perception of the value created for the local community and the audience based on daily experience, feedback and storytelling than on the scorecard imposed by the owners. Measures and indicators are used as additional information to confirm those feelings. 
However, Sundström (2011: 266) acknowledges that when measures are being compared, the reason and the analysis for the existence of a difference can trigger a learning process that may lead to organisational development.

As far as reporting to stakeholders is concerned, Sundström found that measures were provided together with additional narrative information and also visual images on the theatre value creation and mainly with the aim to provide a context in which managers can influence and control how stakeholders interpret measures (id: 273).

It is worthwhile to highlight that intangible performance reporting comes forth as an emotional practice, where creating a feeling of trust is important in order to satisfy the stakeholders and obtain legitimacy (id: 272).

Another fascinating insight into the need to actively engage stakeholders can be found in Dumay (2014), who has outlined a new bottom-up process used to develop a public value creation strategy using the knowledge of the employees of a Conservatorium in Sydney. "First, it emphasises the need to implement actions that promote two way communications between employees, rather than directives that merely present information or instructions to employees.

Second, it also highlights how a narrative approach allows the process of communication to develop, which in turn allows the public value creation strategy to be articulated and visualised. When managers outline a strategy in financial terms, most employees cannot make sense of the argument the numbers make because they are unlikely to have adequate expertise to judge what the numbers mean and take appropriate action" (id: 81).

In particular, what emerges in Dumay's paper is that an action plan is no longer a tool plunging from the top according to a mere technocratic rationale, but it is also part of the creative process and an essential element for the good performance of the cultural initiative itself. In other words, it is an element that does not only reflect the timing, quality, and quantity of resources used but also contributes to the quality of the results.

Finally, a recent research stream is defined as the 4th stage of IC research (Dumay 2016). The underlying assumption of these recent studies is that knowledge does not develop within organisations but is generated from a dialogue and a process of osmosis and interchange between the organisations and networks to which they belong and, more generally, the ecosystem with which businesses interact (Bounfour and Edvinsson 2005; Dumay and Garanina 2013).

Applying this new perspective to the cultural sector, Borin and Donato (2015) introduce the concept of IC ecosystems, where the IC perspective is important to enable a new pattern of the governance model. Their research highlights that IC plays a key role in designing, creating and implementing a cultural ecosystem. The analysis underlines that there is a competitive advantage potentially brought about by a suitable IC and knowledge flow management inside those networks.

\subsection{IC communication under a Habermasian perspective}

The creation of IC also has been investigated under a Habermasian perspective (O’Donnell et al. 2000; Yu and Humphreys 2013). In particular, Habermas' theory 
of communicative action can contribute to a better understanding of the dynamic patterns, how IC is constituted and impacts on organizational processes (Habermas 1981). The theoretical figure of Sprechakte (speech acts) analyzes different forms of speech acts: constative speech acts declare something; regulative acts come up with intentions and interpersonal relations; finally, expressive speech acts give account of the subjective reality of the speaker. In this context, Habermas refers to Austin who used as well the notions of performative and illocutionary acts (Austin 1975). Ex post, the majority of earlier contributions could be assessed as constative speech acts (Habermas 1979).

Later on, as outlined above (e.g. Mouritsen 2001; Habersam and Piber 2003), the focus shifted to a performative and discursive understanding of IC, which requires a communicative understanding of several actors. In the terms of Habermas, the speech acts become regulative and expressive.

Also, Yu and Humphrey (2013: 28) argue that the dynamics of intellectual assets cannot be dealt with a static measurement framework: "The theoretical challenge with intellectual capital is that we may be dealing with a phenomenon that cannot, by definition due to its intangible nature, be fully objectified. We need to start thinking about good estimates, rather than exact calculations; we need to think about facilitating this dynamic process of creation rather than the strongly directive, exploitative and controlling managerial approach of the past". (O'Donnell et al. 2000: 190).

Habermas is not in line with a mono-directive rationality. He sees different rationalities and different perspectives in organizations. On the basis of the theory of communicative action, Yu and Humphrey (2013: 30) advocate for another form of rationality: "Habermas provides us with a higher form of rationality that prioritizes decentralized dialogues and perspective-taking. It is worth noting that Habermas's communicative rationality gives rise to two important processual components for learning, i.e. communicative action and critical reflection."

As a consequence, there is a need for a new governance model that includes several actors of the whole cultural ecosystem (Borin and Donato 2015: 298) and enables an interpersonal understanding and a critical reflection of different rationalities. Therefore, an interesting suggestion to conclude our investigation is the need to consider a collective and interpersonal viewpoint for the interests of a plurality of actors involved in cultural initiatives.

\section{Methodology}

Drawing from previous research that highlights some gaps in the study of PCIs (Piber et al. 2017), we aim to gain a deeper understanding of these new phenomena by looking at them through the lens of IC. Precisely, we followed a performative approach (Mouritsen 2006) by adopting the IC perspective as a boundary object (Bowker and Star 1999) to analyse the key actors' behaviours of PCIs. Indeed, PCIs are an interesting arena to test the IC theory in practice; wherein IC works more as an inscription than as a predictive model, its concepts are more related to the 
narrative of achievement than to quantification, and more attention is put on how actors develop value than how to identify a pattern of value creation.

Hence, we carried out an exploratory case study research (Stebbins 2001; Yin 1984, 1993). This field research method allows us to conduct an "empirical inquiry that investigates a contemporary phenomenon within its real-life context, especially when the boundaries between phenomenon and context are not clearly evident" (Yin 1984: 23). Moreover, this method is consistent with our analysis in that: (i) it involves researchers gathering information to provide the clearest possible picture of the phenomenon, (ii) it focuses on current situations, (iii) the researchers cannot manipulate the events, (iv) the research question is about "how" or "why" the events occur (McCutcheon and Meredith 1993: 240).

The exploration focuses on two PCIs: Big City Life, a street art district in Tor Marancia (Rome), and Matera as European Capital of Culture (ECoC) 2019. The selected PCIs can be considered as two maximum variation cases (Flyvbjerg 2001), featuring a broad variety of participation patterns as well as opposing strategies to generate and communicate impact. In both cases, the analysis is mainly developed at a micro (single organisation) and meso (district/city) level.

Empirical information has been gathered through multiple sources of evidence in order to improve the validity and reliability of our findings (Dul and Hak 2008): interviews as primary data; official documents, social media (e.g., Facebook), websites and press releases as secondary data.

Interviews, carried out in 2017, were primarily two semi-structured and in-depth, and twelve were unstructured (Fontana and Frey 1998). As far as the former interviews are concerned, we devised a list of scheduled inquires as an interview guide to ensure a standard approach but, at the same time, allowed the researchers to feel free to pursue other topics that emerged during the interviews. Questions were of an open-ended nature to elicit the most thorough answers from the respondents (Rubin and Rubin 2005). The interviewees were one of the key actors of each initiative: the curator and principal funder of the Big City Life project, and the Vice Mayor and Strategic Planning Councillor of the City of Matera. The first round of face-to-face conversations lasted about two hours, were recorded, and notes were taken. Then, a follow-up meeting for each interviewee took place later to validate the answers and gain more profound insights into some topics.

Additionally, unstructured interviews were carried out. They contributed to a better understanding of the real-life context and the contingent complexity of the phenomena (Qu and Dumay 2011). The interviewees were: the president of the resident association, the project manager of the communication agency, the person responsible for communication of the municipality district, and three inhabitants of Tor Marancia (for the Big City Life case); the director and the president of the Matera 2019 foundation, the councilor for social policies of the Matera Municipality, and three citizens of Matera (for the Matera ECoC 2019 case).

Documentary analysis concerned, inter alia, official documents: the first and the second bid books, reports of the formal monitor meetings by the Selection Panel and the Monitoring and Advisory Panel for the Matera ECoC 2019 case; and internal documents: the public announcement and a study of the Quasar Design University for the Big City Life case. 
Given the originality of the topic, whose research is still at an infancy stage and without a well-grounded theory, we seek to gain significant insights into this new issue by applying an exploratory approach (Stebbins 2001) with a bottom-up process.

\section{Two different cases of PCls: Big city life and matera ECoC 2019}

In order to answer the research question, we selected two case studies that represent a broad variety in terms of triggering participation and communicating performance and impact: on the one hand, Big City Life, a street art district in Rome, and, on the other hand, Matera as European Capital of Culture 2019.

Big City Life is a project of public art carried out by a not-for-profit entity (999contemporary) to regenerate an area of the city of Rome, Tor Marancia, both from an urban, cultural and social point of view. In 2015, in a couple of months, about 20 international young artists realised monumental murals on the facades of the buildings of a complex of social housing. The case is relevant as many stakeholders (including the residents) have been participating since the start of the project. The area, once a working-class suburb with petty crimes, is now considered as the first open-air "resident museum" in the world.

In the same year, in southern Italy, Matera, located in the Basilicata region, was selected as European Capital of Culture (ECoC) 2019. The ECoC is an initiative launched in 1985 by the European Union (EU) to promote awareness of the cultural heritage of the member states. To be selected, the cities have to apply and present a plan that shows resources, activities and expected impacts. "Together" was the catchphrase of the Matera ECoC 2019 candidacy program and the title of the first bid book prepared for the application (Dossier 2013). Once designed, Matera started a medium-long term cultural program (2015-2019) to generate an urban renewal and a new model of development, leveraging on knowledge, research, innovation and new technology in a context of sustainability and social cohesion and inclusion. Since participation has been a key feature of the project from the very beginning, the case perfectly qualifies as a PCI.

These two initiatives, even with some elements of similarity, have had different impacts on their stakeholders.

\subsection{Big city life}

Talking about the Big City Life project, the project curator and main funder of the initiative (999contemporary) had the main goal to influence the change, and this happened in different ways indeed. The fame of the artists that realised the graffiti has increased and, consequently, the economic value of their artworks. Moreover, at a social level, the artists are no longer considered as people who spoil the common good. On the contrary, their work is acknowledged: "The artists create beauty from nothing and the residents even started to argue about who would get which painting on their wall" (Big City Life project curator). The local government and the city of 
Rome have benefited a lot from this project, which realised social inclusion, active citizenship, urban regeneration, an increased value of the public heritage and tourism attraction at minimal cost. The same happened to the owner of the complex of social housing (Local Public Housing Entity-ATER), which enjoyed the renewal of the area for free.

Fondazione Roma, a not-for-profit philanthropic entity, one of the main funders of the initiative, considered this project as a way to reach its vision, which is to create a welfare community whereby private and public entities and citizens provide social services on equal terms, to propose a system that leaves scope for social interaction and enables citizens to be directly involved in the management of public goods.

The inhabitants of the district have experienced different values from the project: economic value (e.g., money derived from the royalties or guided tours is used to pay for the heating of the compound); social value (e.g., they created an association of residents to manage the museum); cultural value (e.g., they discuss contemporary art). In particular, the project has had a great impact, and it generated a new identity: "In the past, the residents felt ashamed to say 'I live in Tor Marancia', and now they are proud to reside there." (Big City Life project curator). In the surrounding districts, Tor Marancia has even become a brand of street art, and visitors of Rome have started to visit this area off the beaten tracks. Moreover, within the neighbourhood, a bookshop opened, and a pharmaceutical company restored a school as a direct consequence of the Big City Life project. Therefore, the whole neighbourhood and the whole city benefited from the project since now visitors can experience contemporary art in a new touristic route complementing the traditional cultural heritage sites in the city centre.

\subsection{Matera ECoC 2019}

The Matera ECoC 2019, on the other hand, is a longitudinal process that began in 2008 and will culminate in cultural events and projects in 2019. Therefore, it will produce its impacts at a later time. Different actors, on multilayers, and at different stages, have been involved. We can identify three main phases of the project: (i) the first one, when the Matera 2019 Association (a cultural association of Matera inhabitants) began trying to involve the Matera Community (citizens, local firms, etc.) to gain legitimacy; (ii) the candidacy stage, when the Matera Committee was established, the decision-making process started to be institutionalised although it remains very participatory; (iii) the implementation stage (after the designation), when the governance changed and the initial intention to promote a participatory process finally resulted in an increased bureaucracy and a slowing down of the realisation of program. Several stakeholders were involved in these stages: the funders (Basilicata Region and the city of Matera), who had an active role in the project, the Italian Ministry of Art and Cultural heritage, citizens, visitors, etc. The goal of the first stage, to gain the designation of ECoC, was achieved. The two bid books define principles, the structure of the program, organization, and financing. In the current stage, the implementation phase, the main intermediate goals are related to the process, and the focus is on the definition of an effective governance. 
As we can read in the bid books, "participation" may be regarded as one of the main goal of the overall cultural project (which aims to create a "cultural citizen" that is a responsible, informed inhabitant who understands that culture is a fundamental resource and who actively helps to collaborate and co-create cultural and creative initiatives and take care of the city's cultural patrimony). The Sassi landscape ("here there are no lone houses; everything is connected and interwoven", Dossier 2013: 10), which has been chosen as the brand image for the candidacy, is not only a symbol to reinforce citizens' identity but it also evokes the "desire for involvement and engagement of [...] our population as cultural citizens involved in artistic creation, through acts of social inclusion, [...] and future urban strategies" (id: 10) In particular, the first Dossier "Together", in fact, shows the participative and inclusive character of its elaboration process; many young, small businesses and various cultural and social associations of Matera were engaged in its generation, and more than one hundred citizens have been cited in the bid book as participants in the preparation of Matera ECoC 2019 candidacy (Dossier 2013: 94-95). At the same time, a wide group of "digital" volunteers started to spread and narrate the experiences and the story of Matera's candidacy as ECoC on the website.

The Matera ECoC 2019 project is expected to have a great and multifaceted impact on several categories of stakeholders ranging from institutions at different levels (regional, national and European) to individuals (local inhabitants, visitors and European citizens interested in this cultural manifesto).

Many researchers (Cicerchia 2015, 2016) agree that for Matera ECoC 2019, it is possible to highlight three different expected impacts: social, cultural and economic, which are strictly interweaved. They can be summarised as follows: renewal of the local development model; a new way of tourism for visitors; the proposal of a creative industrial workplace for European youth; and, finally, a new lifestyle model for European citizens.

\section{Analysis of performance measurement and communication practices}

These two cases are very different in terms of performance measurement and communication. For the Big City Life case, there is no formal strategy, plan or measure of performance: "No, we don't use performance measures at all" (Big City Life project curator). The general impression is that clear-cut performance measures would be too fragmented and wouldn't add informational value. On the other hand, for the ECoCs an international framework of good practices exists, and a multidimensional performance system is likely to be implemented according to the recommendations by the European Committee. However, there is no evidence of its usefulness yet.

In the Big City Life project, as already mentioned, we did not find explicit performance measurement practices. However, performance has been assessed and communicated in different ways and at different times. In the beginning, several stakeholders had to evaluate the project to decide whether to cooperate with the private initiative proposed by 999contemporary: the artists, the residents, the municipality, the ATER, the funder Fondazione Roma. Therefore, it is possible to state that the 
absence of explicit measurement practices is compensated by the development of a trust relationship between the different stakeholders. The decisions to join the initiative, authorise the painting of the buildings, and fund the project were primarily based on a personal judgement about the reliability of the not-for-profit entity and, primarily, the main actor behind it. Hence, the expected performance was narrated and displayed by the project curator (e.g., showing the sketches of the paintings) and intuitively perceived by the interested parties. In summary, the mentioned stakeholders have built the performance evaluation on an established trust-relationship with the key actor, namely the project curator of the initiative.

After its realisation, the result of the initiative has been extensively communicated through different channels: a book catalogue, a website, a Facebook page, TripAdvisor, interviews, workshops, guided tours, press release, newspaper articles, magazines, television reportages, etc. This has contributed to spreading the output of the project and communicating its impact to the different stakeholders.

In the second case, the Matera ECoC 2019 project, as we have said, an established set of performance metrics used by the European institutions involved already exists (see European Commission 2016). Each city is responsible for the evaluation of the results of its year as ECoC. The Commission has also established common guidelines and indicators for the cities based on the ECoC general objectives ("Safeguard and promote the diversity of cultures in Europe, highlight the common features they share, increase citizens' sense of belonging to a common cultural space and foster the contribution of culture to the long-term development of cities", European Commission 2016: 6) in order to ensure a coherent and standard approach to the evaluation procedure.

This framework represents the cornerstone of the formal performance measurement regime of the project, and the Matera organising committee intends to establish a multidimensional performance measurement system. However, at the moment (June 2018), the precise structure is under construction.

On the one hand, this signals a lack of managerial attention to the designing and implementation of a formal system of monitoring. On the other, the opinion of Matera's former Vice Mayor and Strategic Planning Counsellor (Matera VM and SPC) is that the performance measurement system should be experienced as a tool to activate participative processes of co-design and co-production with the different actors involved. This requires adaptation and co-evolution, aspects that cannot be reconciled with predefined objectives monitored on a baseline. "One of the value propositions of the Matera ECoC 2019 Project is to help managers build participatory processes, to become aware of them and to govern them. The latter can become a path to growth for the community if guided by a visionary approach. [...] In this sense, the strategic plan is a process, not a document. [...] Participation is a process that takes place through daily actions; it is a continuous process [...]. The result of Matera ECoC 2019 must be the renewal of the souls and minds of people, not a museum or an infrastructure, [...] it is a new way of working to collaborate to make social policy participation policy for development" (Matera VM and SPC).

The dossiers that allowed Matera to be designated as ECoC 2019 presents the list of programmed cultural initiatives, which are part of the candidacy (" $a$ kind of strategic plan" as defined by the Matera VM and SPC) and communicate, summarized 
in catchphrases, the cultural vision of the city: "Together" (Dossier 2013) and its development: "Open to the Future" (Dossier 2014).

In detail, the Matera ECoC 2019 project tries to foster citizen participation, local cohesion, and inclusion: "We need to revitalise local democracy and reinforce reciprocal trust between citizens and our political class" (Dossier 2013: 15).

Furthermore, the bids try to highlight the project as an example for other less developed regions in the Southern Mediterranean Sea. "The idea is making Matera the Southern European centre for high-quality European cultural co-production, connecting with the widest and most varied interdisciplinary range possible of artists, cultural operators and experts" (Dossier 2013: 80).

It will be a challenge to include these specific targets concerning the participatory elements of the initiatives in the performance measurement systems. Hence, the success will also depend on the intensity of participation of local citizens as well as their personal feeling of being involved in the project. "That's why they are called participatory cultural initiatives-because you develop culture. You trigger catalytic processes and something will be created". For this reason, "You cannot intercept and assess local participation through the compilation of questionnaires." (Matera VM and SPC). Insofar, like in the Big City Life case, we can also find a subjective and intuitive component of performance measurement in the project.

Summarising, in the case of Matera ECoC 2019, we found the call for a formalised performance measurement requested by the EU for assessing the ex-post impact of the initiatives, which is not yet implemented. In the bids, we found narrative elements of performance communication explaining and fostering the cultural project vision.

In both cases, consistent with the Donato's findings (2008), we found that IC mainstreaming metric tools have not been effectively implemented, as they do not seem to help to manage relational capital key success factors. On the other hand, key assets of both PCIs (i.e., trust, citizen participation and stakeholders legitimation) is understood through internal and external weak signals coming from personal talks, meetings with key actors, public debates and, even more important, the opinion of influencers in the (local) newspapers and on the website.

\section{A new perspective for (knowledge) narrative in PCls: fostering participation and obtaining stakeholders legitimation}

In PCIs, the specific management challenges, which are fostering participation and obtaining stakeholders legitimation, are supported through a narrative approach. In fact, in both case studies, we discovered that narratives (embedded in the Matera bids and communicated by the project curator of Big City Life) are used to communicate the cultural projects and trigger participation among the different actors involved. In that way, the whole initiative gains the legitimation of the main stakeholders, such as citizens, funders, and public authorities.

The participation and consideration of key stakeholders are crucial for the success of PCIs. By comparing the evidence collected in the cases, we can highlight the following insights — arranged in the following categories: 
- managers and project curators (individuals that play a key role in coordinating and organising the initiative, but also organisations that influence decision-making);

- funders (typically public and not-for-profit institutions, including municipalities, national authorities, and supranational organisations, and also private sponsors);

- key actors directly involved in the co-design and co-production of the expected output and outcomes-here intended as the individuals or the organisations that actively participate in delivering/performing the cultural initiative at different levels and in different ways. Among them the community as well as, in some cases (such as for Big City Life), the artists have a special role;

- expected users/recipients of a specific PCI; not only the citizens and the visitors but all the individuals that share common cultural interests and support the PCI vision and values.

Insights from the case studies show that the success (or failure) of a PCI is related to the management of the interests of multiple stakeholders that often are intertwined. For this reason, a participatory approach used to define shared goals contributes to the achievement of the expected outputs and outcomes. This happened for the Matera ECoC 2019 case, in which the first bid book called "Together" (Dossier 2013) was a tool to increase the participation of key actors (individuals and cultural associations involved in the governance and the design of the project, inhabitants and expected users) and, in the meantime, a communication tool to obtain funders legitimation.

When participation lacked, after the nomination of Matera ECoC 2019, where the governance became more bureaucratic and centralised, conflicts and de-legitimation arose. In the same way, for Big City Life, the personal contact of the project curator with the main stakeholders (residents, artists, funders, local authorities) to gain trust and legitimacy before, as well as the use of different forms of social communication after, enabled the participation and, in the meantime, worked as instruments to show the participation of a broader community interested in the project, nationally and internationally.

To build a successful participatory approach, we discovered that a far-seeing project based on common goals and "a story to be told" are the main drivers. Key actors of the governance have the hard role of keeping the "spirit" of participation alive through storytelling and a continuous exchange of information, knowledge, and feelings with other stakeholders. In doing so, following Catasus et al. (2009), we deem that those actors, through their communication, contribute to the sense-giving processes through which stakeholders are involved.

Furthermore, as Paulus and LeJeune (2013) found, friendship and networking appear to be key factors for the board, helping art organisations to survive and grow. It is possible to claim that, in PCIs, stakeholders' engagement and governance coparticipation are key elements for success.

Accordingly, when the main goal is to increase stakeholders' participation, the use of narrative and storytelling together with a form of visualisation (sketches, drawing, pictures, images) are much more effective (Catasús and Gröjer 2006) than a communication based on rational causal effects because it captures "complex 
experiences that combine sense, reason, emotion and imagination" (Weick and Browning 1986: 250). Moreover, "in the narrative paradigm, when the topic is nontechnical, experts are storytellers just like everyone else, which means that non experts can be more active participants" (ibidem 249).

The first Matera ECoC 2019 bid book called "Together", as well as the trust-relationship established with the project creator for Big City Life, allowed stakeholders to be more active participants and co-creators of the PCI itself. Furthermore, their direct involvement in the communication process enhanced their trust in the storytelling. Like in Sundström (2011), the narrative of performance comes forth as an emotional practice where the feeling of trust is important.

In fact, "reasoning is more than just implicative and inferential. The narrative paradigm [...] presumes that ordinary discourse consists of symbolic action that creates social reality. People [...] judge the reasoning in stories by how well the story hangs together (narrative probability) and how fully it rings true with experience (narrative fidelity)" (Weick and Browning 1986: 255).

To gain participation, we observed that numbers do not suffice and traditional measuring is not a means to activate the organisation per se. People need to trust storytelling when they are an effective part of the story.

\section{Conclusions}

On the basis of the above, we can draw the following basic conclusions. Through the IC lens, it is possible to gain deeper insights into how the PCIs' impact is understood, assessed and communicated to its stakeholders, mainly focusing on relationships with the key actors.

To this end, evidence shows that narratives play a crucial role since they support comprehension of the PCIs' key aspects and their interwoven relations. In the beginning stage, in the Big City Life case, the project curator, presenting the vision of the street art district, persuaded the funders of the project, the institutions and the inhabitants of Tor Marancia of the initiative's opportunities. In the Matera ECoC 2019 case, the bid books communicated the vision of the cultural project, showing broad participation of different stakeholders, and this allowed them to obtain the candidacy by the European Committee.

In addition to narratives, also visualisations play a relevant role. If the project curator of Big City Life is asked about the performance of the initiative, he tells the story and proudly shows the murals of Tor Marancia. This allows him to demonstrate the participation of the people and the unique development of social ties between different stakeholders in the project. Similarly, in the Matera ECoC 2019 case, the Sassi landscape, chosen as the brand image, represents a strong visualization of the cultural background of the initiative. This directs the attention to the main goal of the overall cultural initiative: the development of a new participatory model based on community identity and social inclusion.

Moreover, a condition for narratives and visualisations to make impact understandable and, therefore, to trigger legitimation is the development of a trust relationship with the stakeholders. The two cases showed how the establishment of trust 
is a fundamental element of communicating performance. In Big City Life, visitors can perceive the strong bond of trust of the residents in the project curator, who is able to communicate this support to funders and the authorities. Drawing on Donato's "management by antennae", this could be labelled as "communication by antennae' - a key success factor of the project. In the Matera ECoc 2019 case, a mutual trust relationship among the different stakeholders involved in the co-design of the project is the common ground on which the first bid book "Together" was drawn.

Interestingly enough, for the Big City Life case, traditional performance measures have not been implemented. It would have been easy to count visitors and use this and other key performance indicators for legitimation purposes. However, these metrics have not been used as they cannot properly reflect some key issues of the initiative, like the regeneration of the whole suburb and the quality of triggered social interactions. In the Matera ECoC 2019 case, a performance monitoring framework should still be implemented on the basis of EU-requirements. Currently, the organisers do not see a need for such a framework to manage the project. This brings us to the conclusion that the impact of PCIs has dimensions and interwoven aspects which are not amenable for traditional performance measures. In summary, PCIs trigger a focus on talking and showing to understand, instead of a focus on measuring to understand. IC communication works outside a defined framework of performance measures. The findings are supported by the literature on art management research (e.g., Chiaravaloti and Piber 2011) and some ICAR scholars (among them Sundström 2011). The former argue that performance measurement from the outside is challenging to implement without knowing the context. Both state that narratives and visualisations are able to give a rich picture of the whole situation and can represent the intensity and quality of participatory processes.

Beyond the communication perspective, we also found evidence that narratives and visualisations contributed to the organization and the management of the PCIs. They are giving room for "decentralized dialogues" (Yu and Humprheys 2013: 35) and the development of new movements-representing the lifeworld (Habermas 1981) of culture and society. Accordingly, Habermas' theory of communicative action opens up a new way to understand IC from an intersubjective perspective and explain learning processes and reflexivity. "The phenomena in need of explication in intellectual capital research, however, may not be simple facets of objective nature but the inter-subjective dynamic processes of understanding and agreement at both the interpersonal and intra-psychic levels" (O'Donnell et al. 2000: 191). In communicative processes, individuals reach an understanding between different rationalities. Yu and Humphrey (2013: 29) talk about a "higher form of rationality that exists on an interpersonal level".

In another reference to Habermas, we can conclude that narratives can be understood as Sprechakte (translated as speech acts; Habermas 1979). IC-communication does not only have a constative but also regulative and expressive claims (as well labelled as performative or illocutionary, Austin 1975). This highlights two new perspectives of thinking: On the one hand, we see that IC communication has a direct impact on the social world (intended or unintended). On the other hand, we understand that IC also refers also to the whole ecosystem in which it is embedded. The enabled discourses and the triggered changes and influences on attitudes and 
organizational decisions represent a phenomenon which has not been sufficiently explored so far. Nevertheless, in the two cases, we can clearly see the way how narratives influence and trigger impact in the surrounding ecosystems.

Finally, we can address the question about what the IC-debate can learn from our findings: Firstly, we can see that a widening of the analysis from single units to cultural ecosystems increases the level of understanding. In both cases, the impact of the PCIs can only be seen and understood in its political, social and economic context. Secondly, we can confirm that IC has relevance in the hidden areas of black box capital and other intangible phenomena, where key performance measures find no point of access. In these situations, on the basis of the two cases, we argue for narratives and visualisations. Both can improve the level of understanding beyond measurement and introduce "a special language of soft factors that potentially expands a firm's conceptual territory from a tangible world to an intangible world." (Yu and Humphrey 2013: 37). This is actually not new per se, but it generates new flows of emotional knowledge, new possibilities for a communicative understanding in the sense of Habermas, and a new collective dimension beyond organizational boundaries.

Hence, thinking, talking and understanding IC works better with narratives and visualisations than with performance measures. Thus, in line with Catasus et al. (2007), as far as PCIs are concerned, we can reformulate the often used adage as follows: 'What gets emotionally understood, talked about together and communicated, gets done.'

Acknowledgements Open access funding provided by University of Innsbruck and Medical University of Innsbruck.

Open Access This article is distributed under the terms of the Creative Commons Attribution 4.0 International License (http://creativecommons.org/licenses/by/4.0/), which permits unrestricted use, distribution, and reproduction in any medium, provided you give appropriate credit to the original author(s) and the source, provide a link to the Creative Commons license, and indicate if changes were made.

\section{References}

Austin, J. L. (1975). How to do things with words. Oxford: Oxford University Press.

Beck, U., Lash, S., \& Giddens, A. G. (1994). Reflexive modernization—politics, tradition and aesthetics in the modern social order. Cambridge: Polity Press.

Belfiore, E. (2002). Art as a means towards alleviating social exclusion: Does it really work? A critique of instrumental cultural policies and social impact studies in the UK. International Journal of Cultural Policy, 8(1), 91-106.

Belfiore, E. (2013). The "Rhetoric of Gloom" v. the Discourse of Impact in the Humanities: Stuck in a Deadlock? In E. Belfiore \& A. Upchurch (Eds.), Humanities in the twenty-first century: Beyond utility and markets (pp. 95-110). Basingstoke: Palgrave.

Belfiore, E. (2015). 'Impact', 'value'and 'bad economics': Making sense of the problem of value in the arts and humanities. Arts and Humanities in Higher Education, 14(1), 95-110.

Belfiore, E., \& Bennett, O. (2008). The social impact of the arts: An intellectual history. Basingstoke: Palgrave.

Belfiore, E., \& Bennett, O. (2010). Beyond the "Toolkit Approach": Arts impact evaluation research and the realities of cultural policy-making. Journal for Cultural Research, 14(2), 121-142. 
Borin, E., \& Donato, F. (2015). Unlocking the potential of IC in Italian cultural ecosystems. Journal of Intellectual Capital, 16(2), 285-304.

Bounfour, A., \& Edvinsson, L. (2005). A public policy perspective on intellectual capital. In B. Marr (Ed.), Perspectives on intellectual capital (pp. 170-183). London: Routledge.

Bounfour, A., \& Edvinsson, L. (2012). Intellectual capital for communities. London: Routledge.

Bowker, G. C., \& Star, S. L. (1999). Sorting things out: Classification and its consequences. Cambridge: MIT Press.

Brown, J. S., Denning, S., Prusak, L., \& Groh, K. (2005). Storytelling in organizations: Why storytelling is transforming 21 st century organizations and management. London: Routledge.

Callon, M., \& Latour, B. (1981). Unscrewing the big Leviathan: How actors macro-structure reality and how sociologists help them to do so. In K. Knorr-Cetina \& A. Cicourel (Eds.), Advances in social theory and methodology (pp. 277-303). London: Routledge and Kegan Paul.

Catasús, B., Ersson, S., Gröjer, J. E., \& Wallentin, F. Y. (2007). What gets measured gets ... on indicating, mobilizing and acting. Accounting, Auditing and Accountability Journal, 20(4), 505.

Catasús, B., \& Gröjer, J. E. (2006). Indicators: On visualizing, classifying and dramatizing. Journal of Intellectual Capital, 7(2), 187-203.

Catasus, B., Mårtensson, M., \& Skoog, M. (2009). The communication of human accounts: Examining models of sensegiving. Journal of Human Resource Costing and Accounting, 13(2), 163-179.

Chiaravalloti, F., \& Piber, M. (2011). Ethical implications of methodological settings in arts management research: The case of performance evaluation. The Journal of Arts Management, Law, and Society, 41(4), 240-266.

Chiucchi, M. S. (2013). Intellectual capital accounting in action: Enhancing learning through interventionist research. Journal of Intellectual Capital, 14(1), 48-68.

Chong, D. (2009). Arts management. London: Routledge.

Cicerchia, A. (2015). Planning and reporting the social and economic impacts of culture in ECoC Italian candidate cities: a lost opportunity? Società Italiana degli Economisti, 56.ma Riunione Scientifica Annuale, Università Parthenope di Napoli, 22-24 Ottobre 2015. http://www.siecon.org/online/wpcontent/uploads/2015/10/Planning-the-social-and-economic-impacts-of-culture-ext.pdf. Accessed 1 June 2018.

Cicerchia, A. (2016). Social and economic impacts of culture in ECoC Italian candidate cities. Economia della Cultura, 26(1), 149-164.

Comunian, R. (2010). Rethinking the creative city: The role of complexity, networks and interactions in the urban creative economy. Urban Studies, 48(6), 1157-1179.

Cuganesan, S., \& Dumay, J. (2009). Reflecting on the production of intellectual capital visualisations. Accounting, Auditing and Accountability Journal, 22(8), 1161-1186.

Denzin, N. (2001). The reflexive interview and a performative social science. Qualitative Research, 1(1), 23-46.

Donato, F. (2008). Managing IC by antennae: Evidence from cultural organizations. Journal of Intellectual Capital, 9(3), 380-394.

Dossier (2013). Together, http://www.matera-basilicata2019.it/it/archivi/documenti.html. Accessed 14 April 2017.

Dossier (2014). Open the Future, http://www.matera-basilicata2019.it/it/archivi/documenti.html. Accessed 14 April 2017.

Dul, J., \& Hak, T. (2008). Case study research methodology in business research. Oxford: Butterworth.

Dumay, J. (2014). Developing strategy to create a public value chain. In J. Guthrie, G. Marcon, S. Russo, \& F. Farneti (Eds.), Public value management, measurement and reporting (pp. 65-83). Bingley: Emerald Group Publishing Limited.

Dumay, J. (2016). A critical reflection on the future of intellectual capital: From reporting to disclosure. Journal of Intellectual capital, 17(1), 168-184.

Dumay, J., \& Garanina, T. (2013). Intellectual capital research: A critical examination of the third stage. Journal of Intellectual Capital, 14(1), 10-25.

Ebrahim, A., \& Kasturi Rangan, V. (2014). What impact? A framework for measuring the scale and scope of social performance. California Management Review, 56(3), 118-141.

Edvinsson, L. (2013). IC 21: Reflections from 21 years of IC practice and theory. Journal of Intellectual Capital, 14(1), 163-172.

European Commission (2016). European Capitals of Culture (ECoC) 2020-2033, Guidelines for the cities' own evaluations of the results of each ECoC. https://www.min-kulture.hr/userdocsimages/ 
NAJNOVIJE\%20NOVOSTI/09\%20-\%20Guide\%20to\%20European\%20Capitals\%20of\%20Culture. pdf. Accessed 1 June 2018.

Fletcher, A., Guthrie, J., Steane, P., Roos, G., \& Pike, S. (2003). Mapping stakeholder perceptions for a third sector organization. Journal of Intellectual Capital, 4(4), 505-527.

Flyvbjerg, B. (2001). Making social science matter: Why social inquiry fails and how it can succeed again. Cambridge: Cambridge University Press.

Fontana, A., \& Frey, J. H. (1998). Interviewing. The art of science. In N. K. Denzin \& Y. S. Lincoln (Eds.), Collecting and interpreting qualitative materials (pp. 47-78). Thousand Oaks: Sage.

Gilhespy, I. (2001). The evaluation of social objectives in cultural organizations. International Journal of Arts Management, 4(1), 48-57.

Giuliani, M., \& Marasca, S. (2011). Construction and valuation of intellectual capital: A case study. Journal of Intellectual Capital, 12(3), 377-391.

Gstraunthaler, T., \& Piber, M. (2012). The performance of museums and other cultural institutions. International Studies of Management and Organization, 42(2), 29-42.

Guthrie, J., \& Dumay, J. (2015). New frontiers in the use of intellectual capital in the public sector. Journal of Intellectual Capital, 16(2), 258-266.

Guthrie, J., Dumay, J., Ricceri, F., \& Nielsen, C. (Eds.). (2017). The Routledge companion to intellectual capital. London: Routledge.

Guthrie, J., Ricceri, F., \& Dumay, J. (2012). Reflections and projections: A decade of intellectual capital accounting research. The British Accounting Review, 44(2), 68-82.

Habermas, J. (1979). What is universal pragmatics? In J. Habermas (Ed.), Communication and the evolution of society (pp. 1-68). Boston: Beacon Press.

Habermas, J. (1981). Theorie des kommunikativen Handelns, Volume 1 and 2. Frankfurt am Main: Surhkamp.

Habersam, M., \& Piber, M. (2003). Exploring intellectual capital in hospitals - two qualitative case studies in Italy and Austria. European Accounting Review, 12(4), 753-779.

Haskel, J., \& Westlake, S. (2017). Capitalism without capital: The rise of the intangible economy. New Jersey: Princeton University Press.

Hoffjan, A., \& Schmitting, W. (2003). Terra incognita controlleri. Critical Perspectives on Accounting, 14(7), $707-712$.

Holden, J. (2006). Cultural value and the crisis of legitimacy. London: Demos.

Kaplan, R.S. \& Norton, D.P. (1992). The balanced scorecard: measures that drive performance, Harvard Business Review, January-February, 71-80.

Kelly, M. (2014). Participatory art. Oxford: Oxford University Press.

Kong, E. (2010). Intellectual capital and non-profit organizations in the knowledge economy: Editorial and introduction to special issue. Journal of Intellectual Capital, 11(2), 97-106.

Krug, K., \& Weinberg, C. B. (2004). Mission, money, and merit: Strategic decision making by nonprofit managers. Nonprofit Management and Leadership, 14(3), 325-342.

Kushner, R. J., \& Poole, P. P. (1996). Exploring structure-effectiveness relationships in nonprofit arts organizations. Nonprofit Management and Leadership, 7(2), 119-136.

Lin, C. Y. Y., \& Edvinsson, L. (2010). National intellectual capital: A comparison of 40 countries. Berlin: Springer.

McCutcheon, D. M., \& Meredith, J. R. (1993). Conducting case study research in operations management. Journal of Operations Management, 11(3), 239-256.

Mouritsen, J. (2004). Measuring and intervening: How do we theorise intellectual capital management? Journal of Intellectual Capital, 5(2), 257-267.

Mouritsen, J. (2006). Problematising intellectual capital research: Ostensive versus performative IC. Accounting, Auditing \& Accountability Journal, 19(6), 820-841.

Mouritsen, J., Larsen, H. T., \& Bukh, P. N. (2001). Intellectual Capital and the capable firm: Narrating, visualizing, and numbering for management knowledge. Accounting, Organizations and Society, 26(7), 735-762.

O'Brien, D. (2010) Measuring the Value of Culture: A Report to the Department for Culture Media and Sport. London: DCMS, https://www.gov.uk/government/uploads/system/uploads/attachment_data/ file/77933/measuring-the-value-culture-report.pdf. Accessed 1 June 2018.

O’Donnell, D., O’Regan, P., \& Coates, B. (2000). Intellectual capital: A Habermasian introduction. Journal of Intellectual Capital, 1(2), 187-200.

Oancea, A. (2013). Buzzwords and values: The prominence of "impact" in UK research policy and governance. Research Trends, 33, 6-9. 
Paulus, O., \& Lejeune, C. (2013). What do board members in art organizations do? A grounded theory approach. Journal of Management and Governance, 17(4), 963-988.

Piber M., Biondi L., Demartini P., Marchegiani L., \& Marchiori M. (2017). Pursuing civic engagement through participatory cultural initiatives: Mapping value creation, outcome, performance and legitimacy. In 12th international forum on knowledge asset dynamics (IFKAD 2017) Proceedings, 7-9 June, IKAM - Centro Studi Ricerche: Russia.

Polanyi, M. (1966). The tacit dimension. New York: Doubleday.

Qu, S. Q., \& Dumay, J. (2011). The qualitative research interview. Qualitative Research in Accounting and Management, 8(3), 238-264.

Radbourne, J., Glow, H., \& Johanson, K. (2010). Measuring the intrinsic benefits of arts attendance. Cultural Trends, 19(4), 307-324.

Radbourne, J., Johanson, K., Glow, H., \& White, T. (2009). The audience experience: Measuring quality in the performing arts. International Journal of Arts Management, 11(3), 16-29.

Rubin, H. J., \& Rubin, I. S. (2005). Qualitative interviewing. The art of hearing data. Thousand Oaks: SAGE.

Schiuma, G., Lerro, A., \& Carlucci, D. (2008). The knoware tree and the regional intellectual capital index: An assessment within Italy. Journal of intellectual capital, 9(2), 283-300.

Soren, B. J. (2000). The learning cultural organization of the millennium: Performance measures and audience response. International Journal of Arts Management, 2(2), 40-49.

Stebbins, R. A. (2001). Exploratory research in the social sciences. Thousand Oaks: SAGE.

Sundström, A. (2011). Framing numbers "at a distance": Intangible performance reporting in a theater. Journal of Human Resource Costing and Accounting, 15(4), 260-278.

Weick, K. E., \& Browning, L. D. (1986). Argument and narration in organizational communication. Journal of Management, 12(2), 243-259.

Weinstein, L., \& Bukovinsky, D. (2009). Use of the balanced scorecard and performance metrics to achieve operational and strategic alignment in arts and culture not-for-profits. International Journal of Arts Management, 11(2), 42-55.

Yin, R. K. (1984). Case study research: Design and methods. Thousand Oaks: SAGE.

Yin, R. K. (1993). Applications of case study research. Newbury Park: Sage Publishing.

Yu, A., \& Humphreys, P. (2013). From measuring to learning?-Probing the evolutionary path of IC research and practice. Journal of Intellectual Capital, 14(1), 26-47.

Zambon, S. (2016). Ten years after: The past, the present and the future of scholarly investigation on intangibles and intellectual capital. Journal of Intellectual Capital, 17(1), 2-10.

Martin Piber studied at the University of Graz/Austria and at the University of St. Gallen in Switzerland. Now he is professor at the Department of Organization and Learning and head of the research centre of Organization Studies at Leopold-Franzens-Universität in Innsbruck/Austria. He is and has been teaching in several bachelor, master-, PhD-, and further education programs in Austria, Germany, Italy, South Africa, Spain, and Sweden. His research and his publications focus on practices and theory of management control and performance measurement, intellectual capital, the management of cultural organizations, the relevance of art and culture for society, aesthetics, and business ethics. He was visiting professor at the Macquarie University in Sydney/Australia, the Università degli Studi di Pavia/Italy, the University of Cape Town/South Africa and the University of Stockholm in Sweden. Since 2015 he is scientific director of the executive MBA program of the University of Innsbruck.

Paola Demartini is Full Professor of management and accounting at the University of Rome TRE. She is executive Editor of the review Small Business/Piccola Impresa and Vice President for Italy of the European Council for Small Business (ECSB). She is also Director of the Corporate Governance Lab at Roma TRE University. She is enrolled in the MIUR expert peer-reviewer' list and has been responsible for several research projects, including projects funded by the Croatian Ministry and the TEKES (The Finnish funding Agency for Innovation). Her research interests include small business management, corporate financial communication and intellectual capital reporting.

Lucia Biondi is Assistant Professor in Business Administration at the Department of Business Studies,University of "Roma Tre", where she teaches Planning \& Control and Accounting. She has been visitingscholar at the University of Edinburgh-Business School. Cultural heritage has been one of her 
mainresearch topics since her Ph.D. studies. Her research interests include also: Public SectorAccounting, Performance Management, Management Control, Fiscal Agencies.

\section{Affiliations}

\section{Martin Piber ${ }^{1} \cdot$ Paola Demartini ${ }^{1,2} \cdot$ Lucia Biondi $^{1,2}$}

$\bowtie$ Martin Piber

martin.piber@uibk.ac.at

1 Universität Innsbruck, Innsbruck, Austria

2 Università degli Studi Roma Tre, Rome, Italy 